\title{
Palladium-Catalyzed Formal (4+2) Cycloaddition between Alkyl Amides and Dienes Initiated by the Activation of $\mathrm{C}(\mathrm{sp} 3)-\mathrm{H}$ Bonds
}

Borja Cendón, Marc Font, José L. Mascareñas, and Moisés Gulías

\section{Accepted Manuscript}

This document is the Accepted Manuscript version of a Published Work that appeared in final form in ACS Catal., copyright (c) 2020 American Chemical Society after peer review and technical editing by the publisher. To access the final edited and published work see: https://doi.org/10.1021/acscatal.0c00664

\section{Cite this:}

ACS Catal. 2020, 10, XXX, 3425-3430

\section{Copyright information:}

(C) 2020 American Chemical Society 


\title{
Palladium-catalyzed formal (4+2) cycloaddition between alkyl am- ides and dienes initiated by the activation of $\mathrm{C}\left(\mathrm{sp}^{3}\right)-\mathrm{H}$ bonds
}

\author{
Borja Cendón, Marc Font, José L. Mascareñas, ${ }^{*}$ Moisés Gulías* \\ Centro Singular de Investigación en Química Biolóxica e Materiais Moleculares (CIQUS) and Departamento de Química \\ Orgánica. Universidade de Santiago de Compostela, 15782, Santiago de Compostela.
}

\begin{abstract}
We report a formal (4+2) cycloaddition between alkyl-nosylamides and dienes enabled by a palladium-catalyzed activation of $C\left(s p^{3}\right)-H$ bonds beta to the amide group. This atom economical reaction which proceeds under operationally simple conditions, is compatible with a wide variety of dienes, and provides a straightforward method to assemble different types of saturated lactams. The annulation is favored over alternative pathways in part because of the key role of the extra double bond of the diene partner. The use of suitable nitrogen-based additives as palladium ligands, which enable the $C\left(s p^{3}\right)-H$ activation without interfering in subsequent steps of the catalytic cycle, is also critical for the success of the reaction.
\end{abstract}

KEYWORDS: $C\left(s p^{3}\right)-H$ activation, palladium, dienes, formal cycloaddition, alkyl amides, palladacycle

These last decades have witnessed great progress in the field of transition metal-catalyzed activation (and functionalization) of $\mathrm{C}-\mathrm{H}$ bonds. ${ }^{1}$ While the activation of aromatic $\mathrm{C}\left(\mathrm{sp}^{2}\right)-\mathrm{H}$ bonds has become relatively routine (Figure 1a), the functionalization of more challenging aliphatic $\mathrm{C}\left(\mathrm{sp}^{3}\right)-\mathrm{H}$ bonds has been successfully addressed only recently, especially using palladium (II) catalysts (Figure $1 \mathrm{~b}){ }^{2}$ Despite mechanistic studies are yet scarce, these reactions involve the cleavage of the $\mathrm{C}-\mathrm{H}$ bond, usually via $\mathrm{CMD}$ processes, to give five or six-membered metallacycles, which can be elaborated into different products depending on the coupling partners and reaction conditions. Most of reported examples consist of arylation reactions, but there have been also reports on acetoxylation, halogenation, borylation, or alkenylations processes, among others. ${ }^{3}$

In the case of the activation of $\mathrm{C}\left(\mathrm{sp}^{2}\right)-\mathrm{H}$ bonds, there have also been many contributions on the development of formal metalcatalyzed cycloadditions of heteroatom-containing precursors with unsaturated partners (Figure 1c). These transformations are of great constructive value because they provide a direct, atom economical entry to heterocyclic skeletons. ${ }^{4}$ In these reactions, the metallacyclic intermediates generated after the $\mathrm{C}-\mathrm{H}$ activation step evolve via migratory insertion of the unsaturated reaction partner, followed by reductive elimination, to yield the desired cycloadducts. Curiously, mechanistically related cycloadditions involving the cleavage of $\mathrm{C}\left(\mathrm{sp}^{3}\right)-\mathrm{H}$ instead of $\mathrm{C}\left(\mathrm{sp}^{2}\right)-\mathrm{H}$ bonds (Figure 1d), have not been described. There are some examples of carbonylation reactions of bulky alkyl amines or selected amides (formal $n+1$ annulations) ${ }^{5}$ but we are not aware of formal $(n+2)$ heteroannulations with standard two-carbon unsaturated partners such as alkenes, alkynes or similar. ${ }^{6}$
In order to fill this void, we report, for the first time, a formal (4+2) oxidative cycloaddition reaction involving a palladiumpromoted activation and cleavage of $\mathrm{C}\left(\mathrm{sp}^{3}\right)-\mathrm{H}$ bonds. The reaction, which engages alkyl-nosylamides and dienes, is catalyzed by palladium (II) and provides a straightforward, unconventional entry to saturated lactam heterocycles (Scheme 1). The use of dienes is instrumental for the success of the reaction, likely because of the formation of key $\pi$-allyl intermediates like $\mathbf{B}$ (Scheme 1). We also provide mechanistic data, including the isolation of enlightening palladacycle intermediates.

\section{Oxidative $\mathrm{C}-\mathrm{H}$ functionalizations}

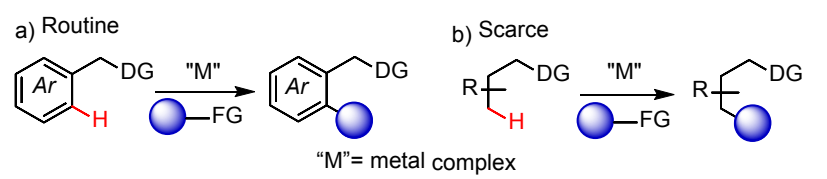

Oxidative (n+2) cycloadditions

c) Routine
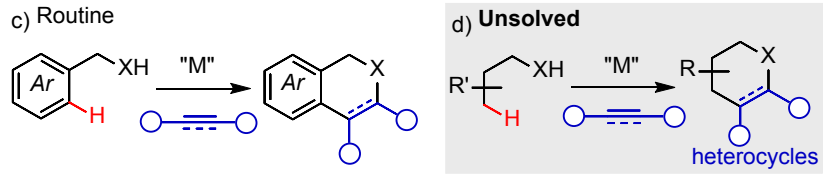

Figure 1. Metal-catalyzed C-H activations.

Our initial experiments were stimulated by previous reports on the palladium-promoted olefination of $\mathrm{N}$-arylpivalamides with activated alkenes like acrylates. ${ }^{7,8}$ These reactions are initiated by an amide-directed $\mathrm{C}-\mathrm{H}$ insertion of $\mathrm{Pd}(\mathrm{II})$ to generate alkylpalladium intermediates, which undergo the migratory insertion of the alkene. However, the resulting palladacycles evolve by $\beta$-hydride elimination instead of by reductive elimination, which precludes the formation of 6-membered cycloadducts. To avoid this last mechanistic step, we considered the use of allenes instead of alkenes as reaction partners. ${ }^{9}$ However, after an intense screening of reaction conditions, the desired formal $(4+2)$ cycloadduct was obtained in yields lower than $30 \%$.

Scheme 1. This work: Pd-catalyzed formal (4+2) cycloaddition with cleavage of a $\mathrm{C}\left(\mathrm{sp}^{3}\right)-\mathrm{H}$ bond

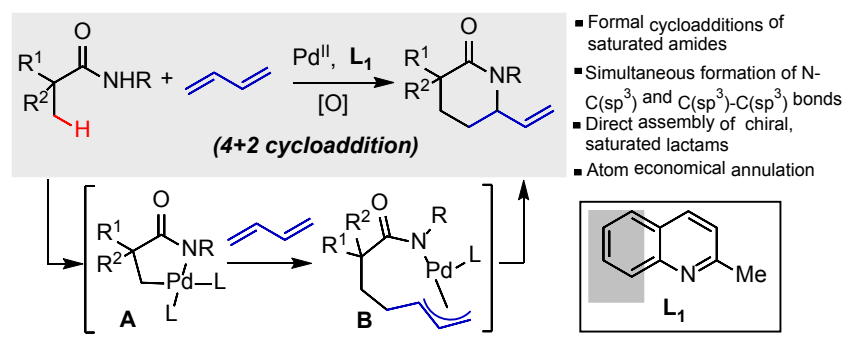


At this point, we thought that dienes might be more suitable reaction partners, owing to the "diene effect". ${ }^{10}$ The presence of the extra double bond provides an additional binding ligand for the metal, which should favor the desired reductive elimination paths. Therefore, we made an extensive screening of conditions for the annulation between pivalamides and (E)-buta-1,3-dien-1ylbenzene (2a), with parallel testing of different parameters (Table 1). We were pleased to find that the desired (4+2) annulation reaction can be achieved by using $10 \mathrm{~mol} \%$ of $\mathrm{Pd}(\mathrm{OAc})_{2}$ and 30 mol\% of quinaldine (L1, inexpensive and commercially available), in DCE at $110^{\circ} \mathrm{C}$, and in presence of 0.5 equiv of $\mathrm{Cu}(\mathrm{OAc})_{2}$ as oxidant. The lactam product 3aa, which exhibits a trans configuration in the remaining double bond, was obtained in $99 \%$ yield and with complete chemoselectivity.

\section{Table 1. Optimization of the reaction conditions}

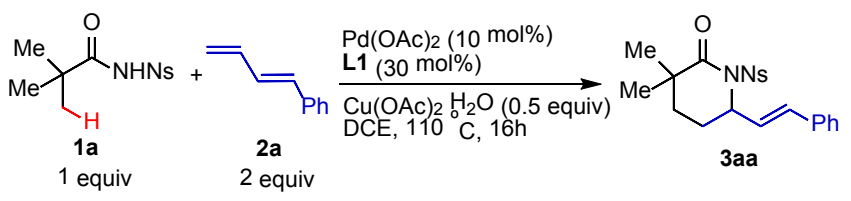

\begin{tabular}{|c|c|c|}
\hline Entry & Deviation from above conditions ${ }^{a}$ & Yield $^{\prime}$ \\
\hline 1 & none & $99 \%$ \\
\hline 2 & Tf instead of Ns & $0 \%$ \\
\hline 3 & 4- $\mathrm{CF}_{3} \mathrm{C}_{6} \mathrm{~F}_{4}$ instead of $\mathrm{Ns}$ & $16 \%$ \\
\hline 4 & Aminoquinoline instead of $\mathrm{Ns}$ & $0 \%$ \\
\hline 5 & $\mathrm{Ag}_{2} \mathrm{CO}_{3}$ (2.5 equiv) as oxidant & $46 \%^{c}$ \\
\hline 6 & $\mathrm{Ag}_{3} \mathrm{PO}_{4}$ (1 equiv) as oxidant & $38 \%$ \\
\hline 7 & Toluene instead of DCE & $28 \%$ \\
\hline 8 & TFT instead of DCE & $39 \%$ \\
\hline 9 & HFIP instead of DCE & $0 \%$ \\
\hline 10 & Dioxane instead of DCE & $39 \%$ \\
\hline 11 & Without L1 & $<5 \%$ \\
\hline
\end{tabular}

${ }^{a}$ Reactions conducted in 0.20 mmol scale. ${ }^{b}$ Isolated yields. ${ }^{c}$ $\mathrm{NaOAc}$ (4 equiv) added.

This screening revealed that the substituent at the amide nitrogen plays a key role in the efficiency of the reaction. Therefore, changing the nosyl for triflate is detrimental, and does not lead to the cyclic product (entry 2). ${ }^{11}$ Furthermore, in contrast with previously described palladium-promoted arylations or alkenylations of pivalic amides, a secondary amide featuring a polyfluorinated aromatic substituent also gave poor results. ${ }^{7 \mathrm{a}, 8}$ Importantly, amides with a bidentate aminoquinoline auxiliary, widely used in $\mathrm{C}-\mathrm{H}$ functionalization reactions, ${ }^{12}$ were completely ineffective (entry 4), with the starting materials being recovered. Regarding oxidants, copper acetate was the most effective, while silver acetate or silver phosphate were less efficient even when used in stoichiometric quantitites (entries 5, 6). We also tested several solvents (entries 7-10), but DCE was found to be optimal.

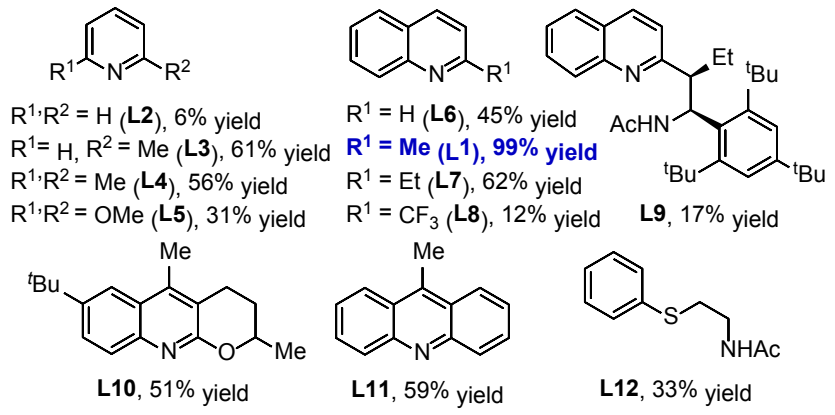

The discovery of $\mathbf{L 1}$ as the optimal ligand came after screening many other possibilities. As indicated in the Figure 2, pyridines or quinolines with ortho methyl groups ( $\mathbf{L 3}, \mathbf{L 4}$, and $\mathbf{L 1})$ or ortho ethyl groups (L7) were the most effective, while those with an additional ring (L10, L11) led to lower yields. Bidentate ligands like $\mathbf{L 9}$ and $\mathbf{L 1 2}$, previously used in $\mathrm{C}-\mathrm{H}$ activation processes, provided low yields. ${ }^{13,7 a}$ Pyridine (L2) was also a poor ligand; and importantly, in the absence of ligands, the reaction does not proceed

With the optimized conditions in hand, we investigated the reaction scope using a variety of commercial and non-commercial dienes (Table 2). Dienes bearing aromatic groups presenting different electronic properties in the terminal position worked nicely, leading to high reaction yields (3ab-3ad, 72-99\% yield). Alkyl substituents are also well tolerated (3ae, 91\%, 3af, 65\%). Noticeably, a diene equipped with a strongly electronwithdrawing group reacts through the terminal double bond with complete chemoselectivity ( $\mathbf{3 a g}, 82 \%$ yield).

\section{Table 2. Scope of the reaction ${ }^{a}$}
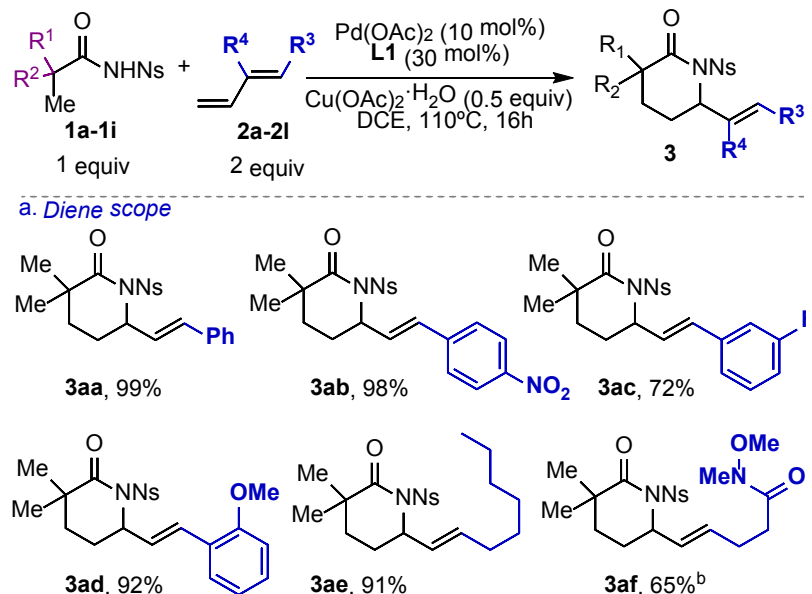<smiles>CCOC(=O)/C=C/C1CCC(C)(C)C(=O)N1S(C)(=O)=O</smiles><smiles>C=C(C)C1CCC(C)(C)C(=O)N1S(C)(=O)=O</smiles><smiles>CC(=Cc1ccccc1)C1CCC(C)(C)C(=O)N1S(C)(=O)=O</smiles>
3ai, $60 \%$ Me<smiles>CC(=CCO[SbH3])C1CCC(C)(C)C(=O)N1S(C)(=O)=O</smiles>

ah, $73 \%$

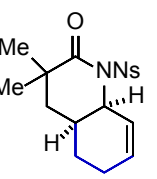

3al, $44 \%^{e}$

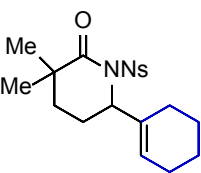

3ak, $63 \%^{c}$

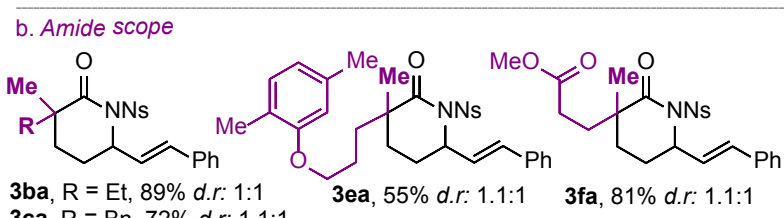

3ba, $\mathrm{R}=\mathrm{Et}, 89 \%$ d.r: $1: 1$ 3ca, $\mathrm{R}=\mathrm{Bn}, 72 \%$ d.r: $1.1: 1$

3da, $\mathrm{R}=\mathrm{Bu}, 56 \%$ d.r: $1: 1$
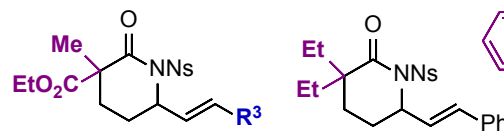

3ga, $\mathrm{R}^{3}=\mathrm{Ph}, 99 \%$, d.r: 1.1:1 3ha, $62 \%^{f}$

3gb, $\mathrm{R}^{3}=p-\mathrm{NO}_{2} \mathrm{Ph}, 96 \%$, d.r: $1.4: 1$

3gg, $\mathrm{R}^{3}=\mathrm{CO}_{2} \mathrm{Et}, 68 \%$, d.r: 1.1:1

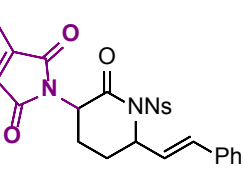

3ia, $57 \%$, d.r: $1.6: 1$

Figure 2. Screening of ligands under optimized conditions 
$a$ Reactions conducted in $0.20 \mathrm{mmol}$ scale. ${ }^{b} 1$ equiv $\mathrm{Cu}(\mathrm{OAc})_{2} \cdot \mathrm{H}_{2} \mathrm{O} .{ }^{c} 10$ equiv of diene. ${ }^{d} 3$ equiv of diene ${ }^{e} 60$ mol\% L1, 1 equiv $\mathrm{Cu}(\mathrm{OAc})_{2} \cdot \mathrm{H}_{2} \mathrm{O} .{ }^{f}$ Another $10 \mathrm{~mol} \%$ of $\mathrm{Pd}(\mathrm{OAc})_{2}$ was added after $7 \mathrm{~h}$.

The reaction also works with dienes featuring substituents in other positions. Thus, commercially available isoprene led to $73 \%$ of the expected product (3ah), although we had to use 10 equivalents of the reactant because of its high volatility. More elaborated 1,2-disubstituted dienes were also effective (3ai-3ak, 52-63\% yields). Notably challenging cyclohexa-1,3-dienes led to the formation of relevant bicyclic structures, although in moderate yield (3al, 44\% yield).

We also investigated the scope with regard to the aliphatic amides, using diene $\mathbf{2 a}$ as model reacting partner. As shown in table $2 b$, in general, $\alpha, \alpha$-disubstituted propanamides gave the expected cycloadducts in good yields (3ba-3ga), which was particularly high in the case of substrates with an alpha-ester group (product 3ga, 99\% yield). These annulations are extensible to other dienes (e.g 3gb and 3gg, 96\% and 68\% yield respectively). $\alpha$-Tertiary amides, like isobutyramide also work, albeit with lower yields, and produce a chromatographically inseparable mixture of lactams and $\alpha, \beta$-unsaturated lactams (1:2 ratio). However, the alanine-derived amide $\mathbf{1 i}$ was an effective partner, as exemplified by the formation of products 3 ia $\left(57 \%\right.$ yield). ${ }^{14}$

Mechanistically relevant, the reaction of diastereoisomeric dienes $(E)-\mathbf{2} \mathbf{m}$ and $(Z)-\mathbf{2 m}$ with $\mathbf{1 a}$ gave the same lactam product (3am), with $E$ stereochemistry in the remaining alkene, although in different yield $[73 \%$ for $(E)-\mathbf{2 m}$ and $24 \%$ for $(Z)-\mathbf{2 m}$, Scheme $2]$. This is consistent with the presence of a $\pi$-allyl intermediate (B. Scheme 1), while the differences in yield suggest that the migratory insertion of the cis-diene presents a higher activation barrier.

Scheme 2. Comparison of reactivity between cis and trans dienes

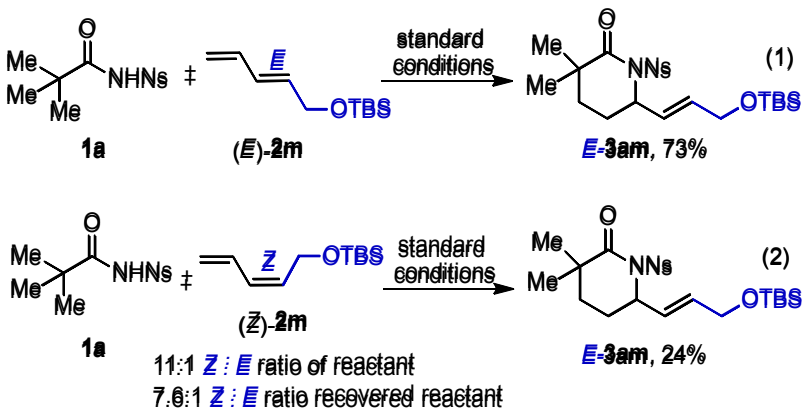

The "diene effect" not only favors the cycloaddition pathway but also the overall reactivity. Thus, when we used 1-octene as reaction partner for the nosylamide 1a, we observed mixtures of olefination products in less than $10 \%$ yield.

In order to further understand the critical role of the ligands, we pursued the isolation of palladium complexes resulting from the $\mathrm{C}-\mathrm{H}$ activation step. Heating a mixture of amide $\mathbf{1 a}$ with equimolar amounts of $\mathrm{Pd}(\mathrm{OAc})_{2}$ and 2 equiv of $\mathbf{L 1}$ (1h in DCE under reflux), allowed for the isolation of the 5-membered palladacycle 4 in $82 \%$ yield (Scheme 3, hydrogens of X-Ray structures omitted for clarity). The crystal structure shows a distorted square-planar geometry with only one quinoline ligand coordinated to palladium and in trans position to the amide group. ${ }^{15}$ One molecule of water (adventitious) occupies one of the fourth coordination positions. The $\mathrm{Pd}-\mathrm{O}$ bond is very long $(2.21 \AA)$, because of the trans effect of the alkyl group, highlighting the lability of the aquo ligand. Treatment of complex $\mathbf{4}$ with 2 equiv of diene 1a for 3 hours leads to an almost quantitative formation of the cycloadduct 3aa, indi- cating that this palladacycle is part of the catalytic cycle, and that the oxidant is not involved in the cycloaddition mechanism. Not surprisingly, complex $\mathbf{4}$ is also a competent catalyst for the reaction.

Remarkably, heating substrate 1a with stoichiometric amounts of $\mathrm{Pd}(\mathrm{OAc})_{2}$, but in the absence of $\mathbf{L 1}$, failed to give any product, thereby indicating the critical role of the nitrogenated ligand. Moreover, when the stoichiometric experiment was carried out with pyridine (L2) instead of quinaldine (L1), we isolated a palladacycle similar to $\mathbf{4}$, but with two pyridine ligands attached to the palladium (5). This result could be explained in terms of the smaller size of pyridine compared to quinaldine. Again, the pyridine trans to the alkyl group has an elongated $\mathrm{Pd}-\mathrm{N}$ bond, suggesting that this is the most labile position $(2.17 \AA$ vs $2.05 \AA$ ). Complex 5, when treated with the diene under standard conditions, led to the corresponding product $\mathbf{3 a a}$ in only $15 \%$ yield. This much lower reactivity with respect to complex 4 , might be associated to the difficulties in releasing the pyridine compared to the aquo ligand. The higher reactivity achieved with ligand L1 might be related with obtaining an appropriate steric balance around the metal center.

\section{Scheme 3. Isolation of key intermediates}

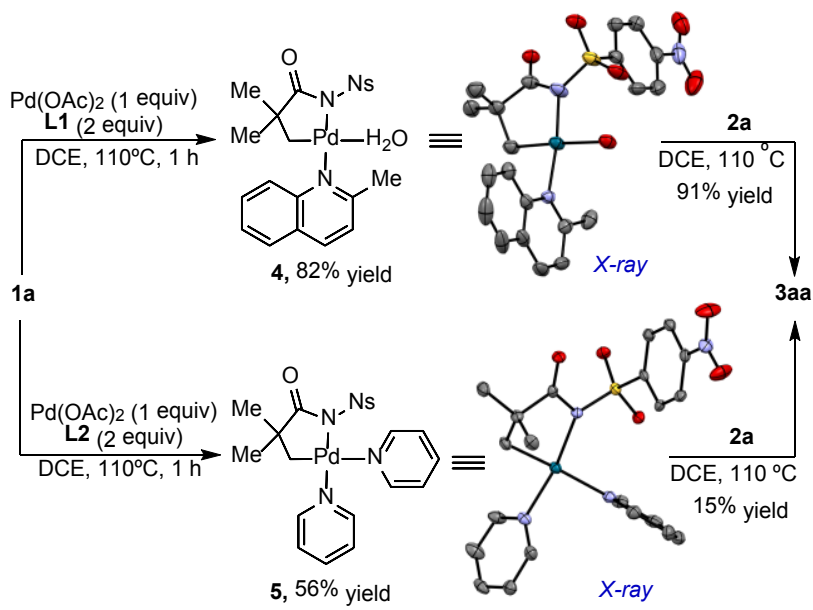

We have also been able to isolate a palladacycle resulting from the substrate containing a bidentate aminoquinoline ligand (6). Importantly, this complex didn't react with the diene when submitted to standard annulation conditions (Scheme 4). This result confirms that the bidentate ligand is suitable for the $\mathrm{C}-\mathrm{H}$ activation, but compromises the subsequent steps of the cycloaddition, likely by hampering a suitable coordination of the diene.

\section{Scheme 4. Isolation of complex 6}

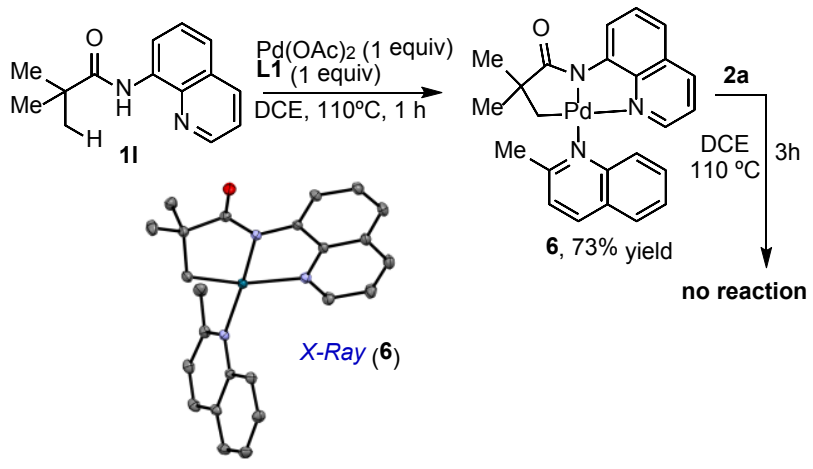

All together, these results allow us to draw a plausible catalytic cycle (Scheme 5). Quinaldine (L1) likely plays a key initial role in promoting the formation of active monomeric species of type $\mathbf{I}$, 
which might prevail over resting species like $\mathbf{A}^{\prime}$ because of the steric properties of the ligand. The relatively high acidity of the amide facilitates the formation of amidopalladium complexes like II, responsible for the $\mathrm{C}-\mathrm{H}$ activation step. The steric properties of the ligand not only avoid the coordination of two amide substrates, but could also favor the concerted metalation deprotonation process that yields palladacycles like 4 . The bidentate characteristics of the diene probably facilitates the release of labile ligands and the formation of complexes required for the migratory insertion step, to give palladium $\pi$-allyl intermediates of type IV. Importantly, the extra coordination site provided by the diene partner is instrumental in favoring a reductive elimination versus non-desired $\beta$-hydride elimination paths. The resulting palladium (0) species are reoxidized by copper (II) acetate to restart the catalytic cycle.

\section{Scheme 5. Proposed mechanistic cycle}

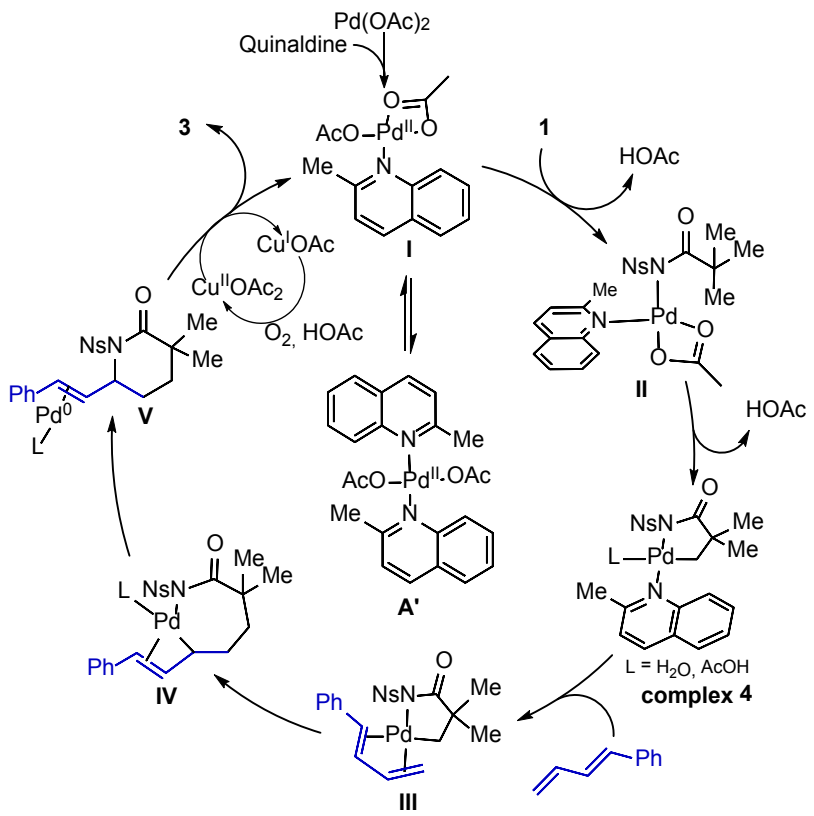

The lactam skeletons resulting from the above cycloadditions can be elaborated in divergent, synthetically appealing ways. The nosyl group is easily removed using tiophenol to form the free lactam product 7 , which can be reduced to the corresponding piperidine by treatment with LAH (8, Scheme 6). Moreover, hydrolysis of 3aa with sodium hydroxide leads to the $\delta$-amino acid 9 , a product that can be formally considered as the result of a chemo- and regioselective 1,2-carboamination of $\mathbf{2 a}$, an otherwise unfeasible transformation. ${ }^{16}$

Scheme 6. Manipulation of the cycloadducts

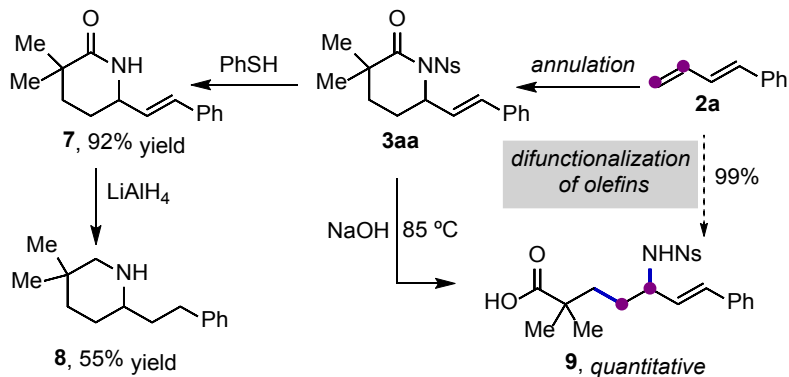

In summary, we have developed a palladium (II)-catalyzed formal $(4+2)$ cycloaddition between readily available aliphatic amides and dienes to give a variety of saturated lactams. To the best of our knowledge, this represents the first demonstration of a $(4+2)$ cycloaddition involving the activation and cleavage of nonactivated $\mathrm{C}\left(\mathrm{sp}^{3}\right)-\mathrm{H}$ bonds, and which proceeds through standard migratory insertion/reductive elimination mechanisms. Our study has also demonstrated that the denticity of the directing groups and the structure of the ligands play a decisive role in the reactivity. Moreover, the presence of a conjugated double bond in the alkene partner is key for the success of the transformation. Considering the relevance that related annulations engaging $\mathrm{C}\left(\mathrm{sp}^{2}\right)-\mathrm{H}$ bonds have achieved, we foresee that our discovery will trigger the development of other type of formal cycloadditions that can further advance the field of synthetic chemistry.

\section{AUTHOR INFORMATION}

\section{Corresponding Author}

*E-mail: moises.gulias@usc.es 0000-0001-8093-2454 joseluis.mascarenas@usc.es 0000-0002-7789-700X

\section{Notes}

The authors declare no competing financial interests.

\section{ASSOCIATED CONTENT}

\section{Supporting Information}

The Supporting Information is available free of charge on the ACS Publications website.

Experimental procedures and spectroscopic data for new compounds (PDF)

CIF files for compounds 3aa, 3af, complex 4, complex 5 and complex 6

\section{ACKNOWLEDGMENT}

This work has received financial support from Spanish grants (SAF2016-76689-R, CTQ2016-77047-P, and FPI fellowship to B. C. and Juan de la Cierva to M. F.), the Consellería de Cultura, Educación e Ordenación Universitaria (ED431C 2017/19, 2015CP082 and Centro singular de investigación de Galicia accreditation 2019-2022, ED431G 2019/03), the European Regional Development Fund (ERDF), and the European Research Council (Advanced Grant No. 340055). The orfeo-cinqa network CTQ2016-81797-REDC is also kindly acknowledged

\section{REFERENCES}

(1) (a) Gensch, T.; Hopkinson, M. N.; Glorius, F.; Wencel-Delord, J. Mild Metal-Catalyzed C-H Activation: Examples and Concepts. Chem. Soc. Rev. 2016, 45, 2900-2936. (b) Engle, K. M.; Mei, T.-S.; Wasa, M.; $\mathrm{Yu}$, J.-Q. Weak coordination as a powerful means for developing broadly useful C-H functionalization reactions. Acc. Chem. Res. 2012, 45, 788802. (c) Yeung, C. S.; Dong, V. M. Catalytic Dehydrogenative CrossCoupling: Forming Carbon-Carbon Bonds by Oxidizing Two Carbon-Hydrogen Bonds. Chem. Rev. 2011, 111, 1215-1292. (d) Chen, D. Y.-K.; Youn, S. W. C-H Activation: A Complementary Tool in the Total Synthesis of Complex Natural Products. Chem. Eur. J. 2012, 18, 9452 9474. (e) Chen, Z.; Wang, B.; Zhang, J.; Yu, W.; Liu, Z.; Zhang, Y. Transition Metal-Catalyzed $\mathrm{C}-\mathrm{H}$ Bond Functionalization by the Use of Diverse Directing Groups. Org. Chem. Front. 2015, 2, 1107-1295.

(2) For recent reviews on palladium $\mathrm{C}\left(\mathrm{sp}^{3}\right)-\mathrm{H}$ activations, see: (a) Palladium-Catalyzed $\mathrm{C}\left(\mathrm{sp}^{3}\right)-\mathrm{H}$ Bond Functionalization of Aliphatic Amines He, C.; Whitehurst, W. G.; Gaunt, M. J. Chem. 2019, 5, 1031-1058. (b) Palladium-Catalyzed Transformations of Alkyl C-H Bonds He, J.; Wasa, M.; Chan, K. S. L.; Shao, Q.; Yu, J.-Q. Chem. Rev. 2017, 117, 8754-8786. (c) Baudoin, O. Ring Construction by Palladium(0)-Catalyzed C(sp3)-H Activation. Acc. Chem. Res. 2017, 50, 1114-1123.

(3) For recent reviews on metal $\mathrm{C}\left(\mathrm{sp}^{3}\right)-\mathrm{H}$ activations, see: (a) Zhang, M.; Wang, Q.; Peng, Y.; Chen, Z.; Wan, C.; Chen, J.; Zhao, Y.; Zhang, R.; Zhang, A. Q. Transition Metal-Catalyzed $\mathrm{sp}^{3} \mathrm{C}-\mathrm{H}$ Activation and Intra- 
molecular C-N Coupling to Construct Nitrogen Heterocyclic Scaffolds. Chem. Commun., 2019, 55, 13048-13065. (b) Gandeepan, P.; Müller, T.; Zell, D.; Cera, G.; Warratz, S.; Ackermann, L. 3d Transition Metals for C-H Activation. Chem. Rev. 2019, 119, 2192-2452. (c) Xu, Y.; Dong, G. $\mathrm{sp}^{3} \mathrm{C}-\mathrm{H}$ Activation via exo-Type Directing Groups. Chem. Sci., 2018, 9, 1424-1432. (d) Chu, J. C. K.; Rovis, T. Complementary Strategies for Directed $\mathrm{C}\left(\mathrm{sp}^{3}\right)-\mathrm{H}$ Functionalization: A Comparison of Transition-MetalCatalyzed Activation, Hydrogen Atom Transfer, and Carbene/Nitrene Transfer. Angew. Chem. Int. Ed. 2018, 57, 62-101.

(4) For selected examples, see: (a) Stuart, D. R.; Bertrand-Laperle, M.; Burgess, K. M. N.; Fagnou, K. Indole Synthesis via Rhodium Catalyzed Oxidative Coupling of Acetanilides and Internal Alkynes. J. Am. Chem. Soc. 2008, 130, 16474-16475. (b) Ueura, K.; Satoh, T.; Miura, M. An Efficient Waste-Free Oxidative Coupling via Regioselective $\mathrm{C}-\mathrm{H}$ Bond Cleavage: $\mathrm{Rh} / \mathrm{Cu}$-Catalyzed Reaction of Benzoic Acids with Alkynes and Acrylates under Air. Org. Lett. 2007, 9, 1407-1409. (c) RomanovMichailidis, F.; Sedillo, K. F.; Neely, J. M.; Rovis, T. Expedient Access to 2,3-Dihydropyridines from Unsaturated Oximes by Rh(III)-Catalyzed CH Activation. J. Am. Chem. Soc. 2015, 137, 8892-8895. (d) Seoane, A.; Casanova, N.; Quiñones, N.; Mascareñas, J. L.; Gulías, M. Straightforward Assembly of Benzoxepines by Means of a Rhodium(III)-Catalyzed $\mathrm{C}-\mathrm{H}$ Functionalization of $o$-Vinylphenols. J. Am. Chem. Soc. 2014, 136, 834-837. (e) Quiñones, N.; Seoane, A.; García-Fandiño, R.; Mascareñas, J. L.; Gulías, M. Rhodium(III)-Catalyzed Intramolecular Annulations Involving Amide-Directed C-H Activations: Synthetic Scope and Mechanistic Studies. Chem. Sci. 2013, 4, 2874-2879. (f) For a review on the field: Gulías, M.; Mascareñas, J. L. Metal-Catalyzed Annulations Through Activation and Cleavage of C-H Bonds. Angew. Chem., Int. Ed. 2016, 55, $11000-11019$

(5) (a) Ho, D. K. H.; Calleja, J.; Gaunt, M. J. Palladium(II)Catalyzed $\mathrm{C}\left(\mathrm{sp}^{3}\right)-\mathrm{H}$ Activation of N,O-Ketals towards a Method for the $\beta$ Functionalization of Ketones. Synlett 2019, 30, 454-458. (b) Png; Z. M. Cabrera-Pardo, J. R.; Cadahía, J. P.; Gaunt, M. J. Diastereoselective C-H Carbonylative Annulation of Aliphatic Amines: A Rapid Route to Functionalized $\gamma$-Lactams. Chem. Sci. 2018, 9, 7628-7633. (c) Hogg, K.F; Trowbridge, A.; Alvarez-Pérez, A. Gaunt, M. J. The $\alpha$-Tertiary Amine Motif Drives Remarkable Selectivity for Palladium-Catalyzed Carbonylation of Methylene C-H Bonds. Chem. Sci. 2017, 8, 8198-8203. (d) Cabrera-Pardo, J. R.; Trowbridge, A.; Nappi, M.; Ozaki, K.; Gaunt, M. J. Selective Palladium(II)-Catalyzed Carbonylation of $\beta$ Methylene $\mathrm{C}-\mathrm{H}$ Bonds in Aliphatic Amines. Angew. Chem. Int. Ed. 2017, 56, 11958-11962. (e) Willcox, D.; Chappell, B. G. N.; Hogg, K. F.; Calleja, J.; Smalley, A. P.; Gaunt, M. J. A General Catalytic $\beta-\mathrm{C}-\mathrm{H}$ Carbonylation of Aliphatic Amines to $\beta$-Lactams. Science 2016, 354, 851-857. (f) Li, S.; Chen, G.; Feng. C.-G.; Gong, W.; Yu, J.-Q. Ligand-Enabled $\gamma-\mathrm{C}-\mathrm{H}$ Olefination and Carbonylation: Construction of $\beta$-Quaternary Centers. J. Am. Chem. Soc. 2014, 136, 5267-5270. (g) Wang, P.-L.; Li, Y.; Wu, Y.; Li, C.; Lan, Q.; Wang, X.-S. Pd-Catalyzed $\mathrm{C}\left(\mathrm{sp}^{3}\right)-\mathrm{H}$ Carbonylation of Alkylamines: A Powerful Route to $\gamma$-Lactams and $\gamma$-Amino Acids. Org. Lett. 2015, 17 , 3698-3701. (h) Hernando, E.; Villalva, J.; Martínez, Á.M.; Alonso, I.; Rodríguez, N.; Arrayás, R. G.; Carretero, J. C. Palladium-Catalyzed Carbonylative Cyclization of Amines via $\gamma-\mathrm{C}\left(\mathrm{sp}^{3}\right)-\mathrm{H}$ Activation: LateStage Diversification of Amino Acids and Peptides. ACS Catal. 2016, 6, $6868-6882$.

(6) A few examples of other type of annulations involving the activation of $\mathrm{C}\left(\mathrm{sp}^{3}\right)-\mathrm{H}$ bonds have been reported: (a) Rakshit, S.; Patureau, F. W.; Glorius, F. Pyrrole Synthesis via Allylic $\mathrm{sp}^{3} \mathrm{C}-\mathrm{H}$ Activation of Enamines Followed by Intermolecular Coupling with Unactivated Alkynes. J. Am. Chem. Soc. 2010, 132, 9585-9587. (b) RomanovMichailidis, F.; Ravetz, B. D.; Paley, D. W.; Rovis, T. Ir(III)-Catalyzed Carbocarbation of Alkynes through Undirected Double C-H Bond Activation of Anisoles. J. Am. Chem. Soc. 2018, 140, 5370-5374. (c) Nakao, Y.; Morita, E.; Idei, H.; Hiyama, T. Dehydrogenative [4 + 2] Cycloaddition of Formamides with Alkynes through Double $\mathrm{C}-\mathrm{H}$ Activation. J. Am. Chem. Soc. 2011, 133, 3264-3267. (d) Archambeau, A.; Rovis, T. Rhodium(III)Catalyzed Allylic $\mathrm{C}\left(\mathrm{sp}^{3}\right)-\mathrm{H}$ Activation of Alkenyl Sulfonamides: Unexpected Formation of Azabicycles. Angew. Chem. Int. Ed. 2015, 54, 13337-13340. (e) Bai, D.; Xia, J.; Song, F.; Li, X.; Liu, B.; Liu, L.; Zheng, G.; Yang, X.; Sun, J.; Li, X. Rhodium(III)-Catalyzed Diverse [4 +
1] Annulation of Arenes with 1,3-Enynes via sp $3 / \mathrm{sp}^{2} \mathrm{C}-\mathrm{H}$ Activation and 1,4-Rhodium Migration. Chem. Sci. 2019, 10, 3987-3993

(7) For examples of $\mathrm{C}\left(\mathrm{sp}^{3}\right)-\mathrm{H}$ activation and acrylate coupling, see: (a) Zhuang, Z.; Yu, C.-B.; Chen, G.; Wu, Q.-F., Hsiao, Y.; Joe, C. L.; Qiao, J. X.; Poss, M. A.; Yu, J.-Q. Ligand-Enabled $\beta-\mathrm{C}\left(\mathrm{sp}^{3}\right)-\mathrm{H}$ Olefination of Free Carboxylic Acids. J. Am. Chem. Soc. 2018, 140, 10363-10367. (b) Hea, C.; Gaunt, M. J. Ligand-Assisted Palladium-Catalyzed C-H Alkenylation of Aliphatic Amines for the Synthesis of Functionalized Pyrrolidines. Chem. Sci. 2017, 8, 3586-3592. (c) Stowers, K. J.; Fortner, K. C.; Sanford, M. S. Aerobic Pd-Catalyzed $\mathrm{sp}^{3} \mathrm{C}-\mathrm{H}$ Olefination: A Route to Both NHeterocyclic Scaffolds and Alkenes. J. Am. Chem. Soc. 2011, 133, 65416544. (d) Jiang, H.; He, J.; Liu, T.; Yu, J.-Q. Ligand-Enabled $\gamma-\mathrm{C}\left(\mathrm{sp}^{3}\right)-\mathrm{H}$ Olefination of Amines: En Route to Pyrrolidines J. Am. Chem. Soc. 2016, 138, 2055- 2059. (e) Wasa, M.; Engle, K. M.; Yu, J.-Q. Pd(II)-Catalyzed Olefination of sp ${ }^{3}$ C-H Bonds. J. Am. Chem. Soc. 2010, 132, 3680-3681.

(8) For some examples of arylation reactions with pivalic amides and cyclopropyl amides, see: (a) Wasa, M.; Chan, K. S. L.; Zhang, X.-G.; He, J.; Miura, M.; Yu, J.-Q. Ligand-Enabled Methylene C( $\left.\mathrm{sp}^{3}\right)-\mathrm{H}$ Bond Activation with a Pd(II) Catalyst. J. Am. Chem. Soc. 2012, 134, 1857018572. (b) Chen, G.; Gong, W.; Zhuang, Z.; Andrä, M. S.; Chen, Y.-Q.; Hong, X.; Yang, Y.-F.; Liu, T.; Houk, K. N.; Yu, J.-Q. LigandAccelerated Enantioselective Methylene $\mathrm{C}\left(\mathrm{sp}^{3}\right)-\mathrm{H}$ Bond Activation. Science 2016, 353, 1023- 1027. (c) He, J.; Takise, R.; Fu, H.; Yu, J.-Q. Ligand-Enabled Cross-Coupling of $\mathrm{C}\left(\mathrm{sp}^{3}\right)-\mathrm{H}$ Bonds with Arylsilanes. $J$. Am. Chem. Soc. 2015, 137, 4618-4621. For more examples see reference 2.

(9) Casanova, N.; Del Rio, K. P.; García-Fandiño, R.; Mascareñas, J. L.; Gulías M. Palladium(II)-Catalyzed Annulation Between OrthoAlkenylphenols and Allenes. Key Role of the Metal Geometry in Determining the Reaction Outcome. ACS Catal. 2016, 6, 3349-3353.

(10) Croatt, M. P.; Wender, P. A. The Diene Effect: The Design, Development, and Mechanistic Investigation of Metal-Catalyzed Diene-yne, Diene-ene, and Diene-allene [2+2+1] Cycloaddition Reactions. Eur. J. Org. Chem. 2010, 19-32.

(11) A small amount (less than $30 \%$ ) of an olefinated product was isolated.

(12) Shabashov, D.; Daugulis, O. Catalytic Coupling of C-H and C-I Bonds Using Pyridine as a Directing Group Org. Lett. 2005, 7, $3657-$ 3659 .

(13) (a) Romero E. A; Chen, G.; Gembicky, M.; Jazzar, R.; Yu, J.-Q.; Bertrand, G. Understanding the Activity and Enantioselectivity of Acetyl Protected Aminoethyl Quinoline Ligands in Palladium-Catalyzed beta$\mathrm{C}\left(\mathrm{sp}^{3}\right)-\mathrm{H}$ Bond Arylation Reactions. J. Am. Chem. Soc. 2019, 141, 16726-16733.

(14) An $N$-Boc protected alanine failed to react, which suggests that the phthalimide group on the amine has a positive influence in the reaction. A preliminary assay with a phthalimide protected phenyl alanine led to the recovery of starting material.

(15)For a related palladacyle but with two quinoline-type ligands, see: He, J.; Li, S.; Deng, Y.; Fu, H.; Laforteza, B. N.; Spangler, J. E.; Homs, A.; Yu, J.-Q. Ligand-Controlled $\mathrm{C}\left(\mathrm{sp}^{3}\right)-\mathrm{H}$ Arylation and Olefination in Synthesis of Unnatural Chiral $\alpha$-Amino Acids. Science 2014, 343, 1216 1220.

(16) For recent examples on the difunctionalization of olefins, see: (a) Liu, Z.; Zeng, T.; Yang, K. S.; Engle, K. M. $\beta, \gamma$-Vicinal Dicarbofunctionalization of Alkenyl Carbonyl Compounds via Directed Nucleopalladation. J. Am. Chem. Soc. 2016, 138, 15122-15125. (b) Liu, Z.; Chen, J.; Lu, H.-X.; Li, X.; Gao, Y.; Coombs, J. R.; Goldfogel, M.; Engle, K. M. Pd(0)Catalyzed Directed syn-1,2-Carboboration and -Silylation: Alkene Scope, Applications in Dearomatization, and Stereocontrol via a Chiral Auxiliary. Angew. Chem. Int. Ed. 2019, 58, 17068-17073. (c) Liu, Z.; Ni, H.-Q.; Zeng, T.; Engle, K. M. Catalytic Carbo- and Aminoboration of Alkenyl Carbonyl Compounds via 5- and 6-Membered Palladacycles. J. Am. Chem. Soc. 2018, 140, 3223-3227. (d) Liu, Y., Yang, X., Song, R.; Luo, S., Li, J. Oxidative 1,2-Carboamination of Alkenes with Alkyl Nitriles and Amines Toward $\gamma$-Amino Alkyl Nitriles. Nat. Commun. 2017, 8, 14720. 
$\mathrm{C}\left(\mathrm{sp}^{3}\right)-\mathrm{H}$ activation and formal $(4+2)$ cycloaddition
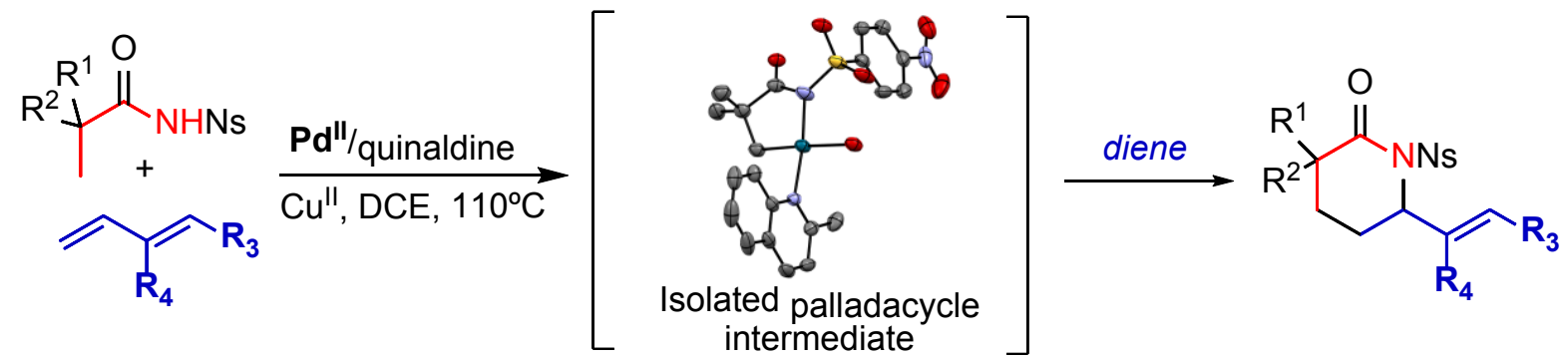